\title{
Mechanism of Mechanochemical C-H Bond Activation in an Azobenzene Substrate by Pd(II) Catalysts
}

\author{
Alen Bjelopetrović, ${ }^{\ddagger[a]}$ Stipe Lukin, ${ }^{\ddagger[a]}$ Ivan Halasz, ${ }^{[a]}$ Krunoslav Užarević, ${ }^{[a]}$ Ivica Đilović, ${ }^{[b]}$ Dajana \\ Barišić, ${ }^{[a]}$ Ana Budimir ${ }^{[c]}$ Marina Juribašić Kulcsár, ${ }^{*[a]}$ and Manda Ćurić ${ }^{\star[a]}$
}

\begin{abstract}
Mechanism of solid-state $\mathrm{C}-\mathrm{H}$ bond activation by various $\mathrm{Pd}(\mathrm{II})$ catalysts under milling conditions has been studied by in situ Raman spectroscopy. Common $\mathrm{Pd}(\mathrm{II})$ precursors, i.e. $\mathrm{PdCl}_{2}$, $\left[\mathrm{Pd}(\mathrm{OAc})_{2}\right]_{3}, \quad \mathrm{PdCl}_{2}(\mathrm{MeCN})_{2}$ and $\left[\mathrm{Pd}(\mathrm{MeCN})_{4}\right]\left[\mathrm{BF}_{4}\right]_{2}$, have been employed for solid-state activation of one or two $\mathrm{C}-\mathrm{H}$ bonds in an asymmetric azobenzene substrate. The $\mathrm{C}-\mathrm{H}$ activation was achieved by all used $\mathrm{Pd}(\mathrm{II})$ precursors and their reactivity increases in the order $\left[\mathrm{Pd}(\mathrm{OAc})_{2}\right]_{3}<\mathrm{PdCl}_{2}(\mathrm{MeCN})_{2}<\mathrm{PdCl}_{2}<$ $\left[\mathrm{Pd}(\mathrm{MeCN})_{4}\right]\left[\mathrm{BF}_{4}\right]_{2}$. In situ Raman monitoring in combination with stepwise ex situ NMR, IR and PXRD experiments has provided direct probing of the reaction mechanism and kinetics, and revealed how liquids of different acid-base properties and proticity as well as selected solids used as additives modify precursors or intermediates and their reactivity. Reaction intermediates that were isolated and structurally characterized agree with the observed species during reaction. In situ Raman spectroscopy has also enabled the derivation of reaction profiles suggesting an electrophilic process which proceeds via a coordination complex (adduct) undergoing deprotonation by a bound or an external base depending on the used $\mathrm{Pd}(\mathrm{II})$ precursor. Slow step of the first palladation for two chloride precursors and $\left[\mathrm{Pd}(\mathrm{MeCN})_{4}\right]\left[\mathrm{BF}_{4}\right]_{2}$ is the $\mathrm{C}-\mathrm{H}$ bond cleavage whereas palladation using $\left[\mathrm{Pd}(\mathrm{OAc})_{2}\right]_{3}$ depends primarily on breaking of its trimeric structure by the azobenzene substrate and/or liquid additives.
\end{abstract}

\section{Introduction}

Ligand-directed $\mathrm{C}-\mathrm{H}$ bond activation with palladium compounds (Fig. 1), i.e. palladation, is an attractive topic of research due to its exceptional importance in synthetic organic chemistry. ${ }^{[1,2]}$ In addition, palladium-mediated $\mathrm{C}-\mathrm{H}$ bond activation is a common method for the synthesis of various palladacycles successfully applied in many areas of material science and biological

[a] A. Bjelopetrović, S. Lukin, Dr I. Halasz, Dr K. Užarević, D. Barišić, M. Juribašić Kulcsar, Dr M. Ćurić)

Division of Physical Chemistry

Ruđer Bošković Institute

Bijenička 54, 10000 Zagreb, Croatia

E-mail: curic@irb.hr, marina.juribasic@irb.hr

[b] Dr I. Đilović

Department of Chemistry

Faculty of Science, University of Zagreb

Horvatovac 102a, 10000 Zagreb, Croatia

[c] Dr A. Budimir

Faculty of Pharmacy and Biochemistry, University of Zagreb

Department of Chemistry

Ante Kovačića 1, 10000Zagreb, Croatia

Supporting information for this article is given via a link at the end of the document.

\section{PALLADIUM(II) PRECURSORS}

1) type $I$ - chloride precursors

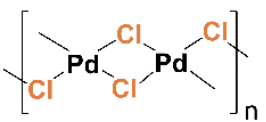<smiles>CN[Pb](Cl)(Cl)NC</smiles>

2) type $/ /$ - ionic precursor

3) type III - acetate precursor<smiles>CN[Pb](NC)(N(C)C)N(C)C</smiles>

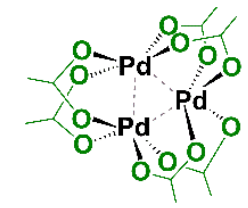

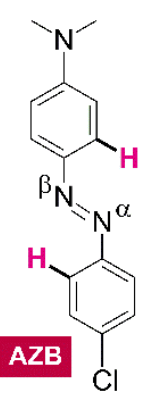
SUBSTRATE

\section{MILLING METHODS}

neat grinding (NG)

liquid-assisted grinding (LAG)

ion-assisted grinding (IAG)

ion-and-liquid-assisted grinding (ILAG)

\section{ADDITIVES:}

liquids: DMF, $\mathrm{H}_{2} \mathrm{O}$,

$\mathrm{AcOH}, \mathrm{MeCN}$

Figure 1. Experimental conditions for solid-state palladation of the substrate AZB by palladium(II) precursors

chemistry. ${ }^{[2-4]}$ Procedures for preparing the palladated compounds are mainly based on reactions in solution. ${ }^{[2,5]}$ Recent advances in solid-state synthetic methods, ${ }^{[6]}$ particularly by ball milling, ${ }^{[7-11]}$ led to the first mechanochemical synthesis of palladacycles via solid-state $\mathrm{C}-\mathrm{H}$ bond activation. ${ }^{[11]}$ The ballmilling procedures proved more advantageous to solution techniques due to much shorter reaction times and achievement of double $\mathrm{C}-\mathrm{H}$ bond activation, producing dipalladated compounds not available from solution. Therein, in situ Raman monitoring has shown that palladation of azobenzene by $\left[\mathrm{Pd}(\mathrm{OAc})_{2}\right]_{3}$ occurs regioselectively, first on the phenyl ring with the electron-donating substituent. ${ }^{[11]}$

As the $\mathrm{C}-\mathrm{H}$ bond activation presents the key step in many catalytic reactions induced by transition metals, ${ }^{[1,2]}$ the first mechanosynthesis of palladacycles via $\mathrm{C}-\mathrm{H}$ bond(s) activation promptly led to the use of mechanochemical methods in metalcatalyzed functionalization of organic molecules. ${ }^{[9,10]}$ Among all used catalysts special attention has been paid to palladium compounds due to their ubiquitous application in catalytic reactions.$^{[1,2]}$ In contrast to solution, ${ }^{[1,5 a]}$ the solid-state $\mathrm{C}-\mathrm{H}$ bond activation in an organic substrate by different palladium catalysts has not been comparatively studied even though a thorough understanding of catalyst's reactivity is essential for the optimization of metal-catalyzed solid-state reactions. Although performing chemical transformations under mechanochemical conditions has a wide application in various branches of chemistry, ${ }^{[7-11]}$ direct probing of the reaction mechanism and kinetics in the solid state has become possible by the 
development of in situ powder X-ray diffraction (PXRD) and Raman monitoring techniques. ${ }^{[12]}$

Herein we report the first comparative mechanistic study of the regioselective solid-state $\mathrm{C}-\mathrm{H}$ bond activation in asymmetric azobenzene substrate (AZB) by most common $\mathrm{Pd}(\mathrm{II})$ catalysts representing monomeric, trimeric and polymeric species as well as an ionic $\mathrm{Pd}(\mathrm{II})$ salt. Milling reactions were performed using liquid and solid additives frequently employed in catalytic reactions (Fig. 1). Detailed mechanistic insight, obtained by in situ and ex situ spectroscopic monitoring along with extraction of reaction profiles by analysis of in situ collected Raman spectra, and accompanied by structural characterization of intermediates, supports the proposed complex multi-step reaction landscape. This study also uncovered the strong effect of liquid and ionic additives on the solid-state palladation pathway that was found to depend on type of the palladium catalyst. Our results provide enhanced and unprecedented understanding of the common first step in many catalytic transformations of organic molecules that undergo activation of the $\mathrm{C}-\mathrm{H}$ bond by palladium compounds in the solid state.

\section{Results and Discussion}

To explore the $\mathrm{C}-\mathrm{H}$ activation in 4-chloro-4'-(N,Ndimethylamino)azobenzene (AZB), we have tested three types of $\mathrm{Pd}$ precursors: type I - neutral chloride complexes polymeric $\mathrm{PdCl}_{2}$ and monomeric $\mathrm{PdCl}_{2}(\mathrm{MeCN})_{2}$; type II monomeric ionic complex $\left[\mathrm{Pd}(\mathrm{MeCN})_{4}\right]\left[\mathrm{BF}_{4}\right]_{2}$; and type III trimeric neutral acetate complex $\left[\mathrm{Pd}(\mathrm{OAc})_{2}\right]_{3}$ (Figure 1). Effect of additives was screened using (I) common liquids: $N, N$ dimethylformamide (DMF), water $\left(\mathrm{H}_{2} \mathrm{O}\right)$, acetonitrile $(\mathrm{MeCN})$ and acetic acid $(\mathrm{AcOH})$; and (ii) solid additives: sodium acetate $(\mathrm{NaOAc})$ and sodium tetrafluoroborate $\left(\mathrm{NaBF}_{4}\right)$. The beneficial action of liquid additives onto palladation, apart from allowing for a greater molecular mobility, ${ }^{[2]}$ may depend on their effect on two reaction steps, i.e. the adduct formation and the $\mathrm{C}-\mathrm{H}$ bond activation. Adding the same amount of the liquid additive $(15 \mu \mathrm{L})$ and keeping the ratio of the total mass of the reaction mixture and the volume of the liquid constant throughout all experiments, allowed for identification of effects of the employed additives. Breaking of the polymeric $\mathrm{PdCl}_{2}$ or trimeric $\left[\mathrm{Pd}(\mathrm{OAc})_{2}\right]_{3}$ is a prerequisite for the adduct formation whereas cleavage of the $\mathrm{C}-\mathrm{H}$ bond requires a suitable proton shuttle for efficient proton elimination. Hence, we have selected liquids with different acidbase properties to test the effect of basicity of additives onto palladation.

AZB was selected as a substrate since it contains para substituents with different electron-donating properties that allows for testing regioselectivity of the $\mathrm{C}-\mathrm{H}$ bond activation in the solid state. AZB can form two isomeric species, alpha and beta, which have the metal coordinated at the alpha or beta azonitrogen (Figure 1) and lead to different reaction paths.

In situ Raman monitoring along with stepwise ex situ infrared (IR), PXRD and nuclear magnetic resonance (NMR) monitoring were conducted in order to track the conversion of reactants, as well as to confirm identity of intermediates and products. We note that the solid-state Raman spectroscopy is a powerful tool for monitoring changes on the azobenzene core as bands originating from phenyl and azo groups give intensive spectral signals. Other used ligands and additives are not clearly observed by Raman and their identification requires employment of other spectroscopic methods.

\section{Reactions with precursors I- $\mathrm{PdCl}_{2}$ and $\mathrm{PdCl}_{2}(\mathrm{MeCN})_{2}$}

Milling experiments. Neat grinding (NG $)^{[7]}$ and liquid-assisted grinding (LAG) $)^{[7]}$ of AZB even with a 4-fold excess of each chloride precursor with respect to AZB led to a mixture of the mono- and dipalladated complexes after 20 hours of continuous milling (Figure S10). Poor reaction outcome was associated with breaking of the palladated products due to the $\mathrm{Pd} / \mathrm{H}$ exchange in presence of a strong acid $\mathrm{HCl}$ that is formed as a byproduct.

In order to avoid $\mathrm{HCl}$ formation and obtain the pure dipalladated product, we have turned to ion-assisted milling. Introduction of two equivalents of $\mathrm{NaOAc}$ to the reaction mixture resulted in formation of $\mathrm{AcOH}$ in ion-assisted grinding $(\mathrm{IAG})^{[7]}$ and ion-and-liquid-assisted grinding (ILAG $)^{[7]}$. Presence of $\mathrm{AcOH}$ was supported by ${ }^{1} \mathrm{H}$ NMR spectra of all bulk mixtures (Figure S11) and confirmed that acetate, as an external base, is the end acceptor of the proton released during palladation.

Table 1. Dipalladation of AZB by chloride Pd(II) precursors in a 1:4 molar ratio in presence of $\mathrm{NaOAc}$

\begin{tabular}{llll}
\hline No. & $\mathrm{Pd} \mathrm{precursor}$ & Liquid & $\mathrm{Time}^{\star} / \mathrm{h}$ \\
\hline 1 & $\mathrm{PdCl}_{2}$ & - & 4.5 \\
2 & $\mathrm{PdCl}_{2}$ & $\mathrm{DMF}$ & 3.5 \\
3 & $\mathrm{PdCl}_{2}$ & $\mathrm{H} \mathrm{O}$ & 2.5 \\
4 & $\mathrm{PdCl}_{2}$ & $\mathrm{MeCN}$ & 11 \\
5 & $\mathrm{PdCl}_{2}$ & $\mathrm{AcOH}$ & 8 \\
6 & $\mathrm{PdCl}_{2}(\mathrm{MeCN})_{2}$ & - & 15 \\
7 & $\mathrm{PdCl}_{2}(\mathrm{MeCN})_{2}$ & $\mathrm{DMF}$ & 5 \\
8 & $\mathrm{PdCl}_{2}(\mathrm{MeCN})_{2}$ & $\mathrm{H}_{2} \mathrm{O}$ & $>20$ \\
9 & $\mathrm{PdCl}_{2}(\mathrm{MeCN})_{2}$ & $\mathrm{MeCN}$ & 20 \\
\hline
\end{tabular}

* Corresponds to time at which full conversion to a chloride dipalladated product is confirmed by NMR and Raman.

IAG reaction of $\mathrm{PdCl}_{2}$ and $A Z B$ in a 4:1 molar ratio with two equivalents of $\mathrm{NaOAc}$ (Table 1), denoted further as IAG/PdCl afforded the dipalladated product after 4.5 hours of milling. Next, we tested the effect of liquids of different acid-base properties and proticity on dipalladation of AZB by chloride precursors. Reaction times needed for the full conversion of AZB to the dipalladated product in ILAG reactions of $\mathrm{PdCl}_{2}$ and $\mathbf{A Z B}$ in a 4:1 molar ratio with $\mathrm{NaOAC}$ increase in the following order of the 

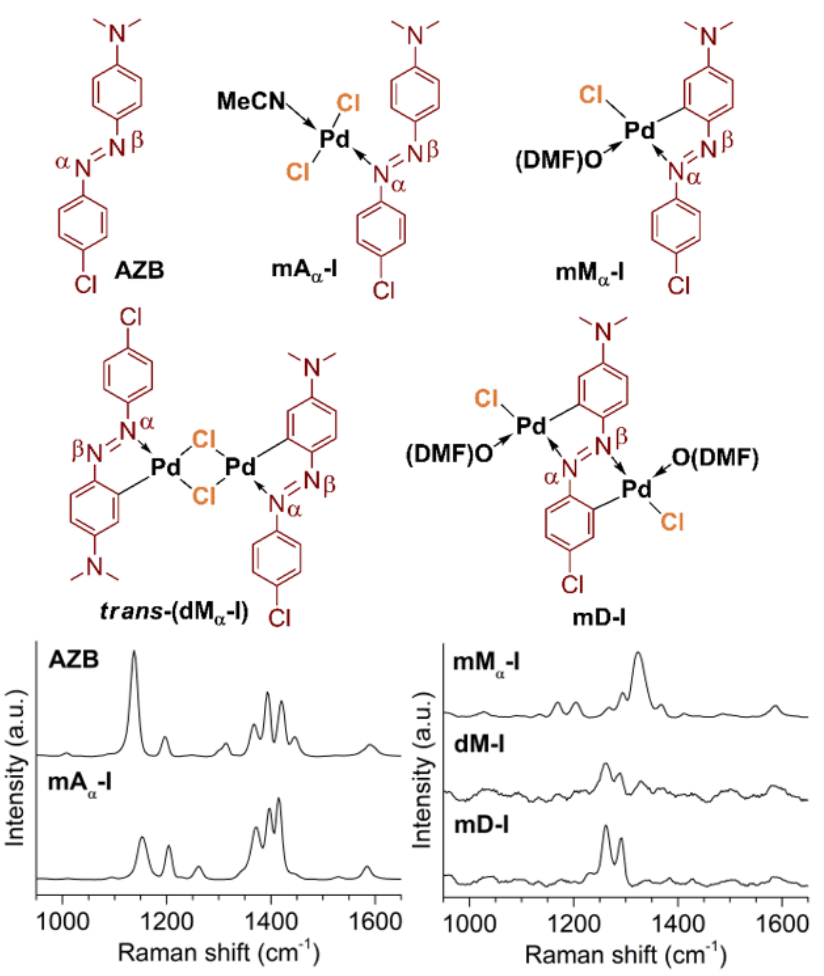

employed liquid additives: $\mathrm{H}_{2} \mathrm{O}<\mathrm{DMF}<$ none $<\mathrm{AcOH}<\mathrm{MeCN}$. A large difference

Figure 2. Structure and selected part of normalized solid-state Raman spectra of AZB monomeric alpha adduct $\left[\mathrm{PdCl}_{2}(\mathbf{A Z B})(\mathrm{MeCN})\right]\left(\mathbf{m A}_{\boldsymbol{\alpha}}-\mathbf{I}\right)$, monomeric alpha monopalladated complex $[\mathrm{PdCl}(\mathbf{A Z B}-\mathrm{H})(\mathrm{O}-\mathrm{DMF})]\left(\mathbf{m M}_{\mathbf{\alpha}} \mathbf{- I}\right)$, dimeric monopalladated complex trans-[PdCl$(\mathbf{A Z B}-\mathrm{H})]_{2} \quad(\mathbf{d M}-\mathrm{I})$, and monomeric dipalladated complex $\left[\mathrm{Pd}_{2} \mathrm{Cl}_{2}(\mathbf{A Z B}-2 \mathrm{H})(\mathrm{O}-\mathrm{DMF})_{2}\right](\mathbf{m D}-\mathbf{I})$.

in duration of the reaction within employed aprotic (DMF and $\mathrm{MeCN})$ as well as within protic $\left(\mathrm{AcOH}\right.$ and $\left.\mathrm{H}_{2} \mathrm{O}\right)$ liquids indicates that proticity is not a key factor in the slow step of the studied palladation reaction by chloride precursors. Quantitative transformation of AZB to the dipalladated product using $\mathrm{PdCl}_{2}(\mathrm{MeCN})_{2}$ was significantly slower than with $\mathrm{PdCl}_{2}$ (Table 1). Analogous IAG and ILAG of AZB and chloride precursors in $1: 1$ and 1:2 molar ratios afford a mixture of AZB, mono- and dipalladated products. This could be due to a side reaction in which the released chlorides consume the $\mathrm{Pd}$ precursor and form chloropalladate species that, according to the study of azobenzene palladation in DMF, ${ }^{[13]}$ undergo cyclopalladation but very slowly thus retarding the reaction.

All tested solid-state procedures for the synthesis of $\mathbf{m D}-\mathbf{I}$ are significantly faster and cleaner than the solution method, which affords the same product after at least 5 days of stirring in DMF. ${ }^{5 a}$

Product isolation and characterization. The product was isolated from the crude mixture by washing with $\mathrm{H}_{2} \mathrm{O}$ and acetone to remove $\mathrm{AcOH}$ and other impurities (sodium chloride, chloropalladate species, etc.). According to IR and NMR, washing removes the coordinated solvents suggesting formation of a solvent-free coordinately-unsaturated, dimeric or polymeric, species with an empirical formula $\left[\mathrm{Pd}_{2} \mathrm{Cl}_{2}(\right.$ AZB-2H) $]$. Recrystallization from DMF of the washed product affords the

Scheme 1. Mechanism of AZB dipalladation by $\mathrm{PdCl}_{2}(\mathrm{DMF})_{2}$ in solution. ${ }^{5 a}$ Only alpha route is drawn. Ancillary ligands are omitted for clarity.
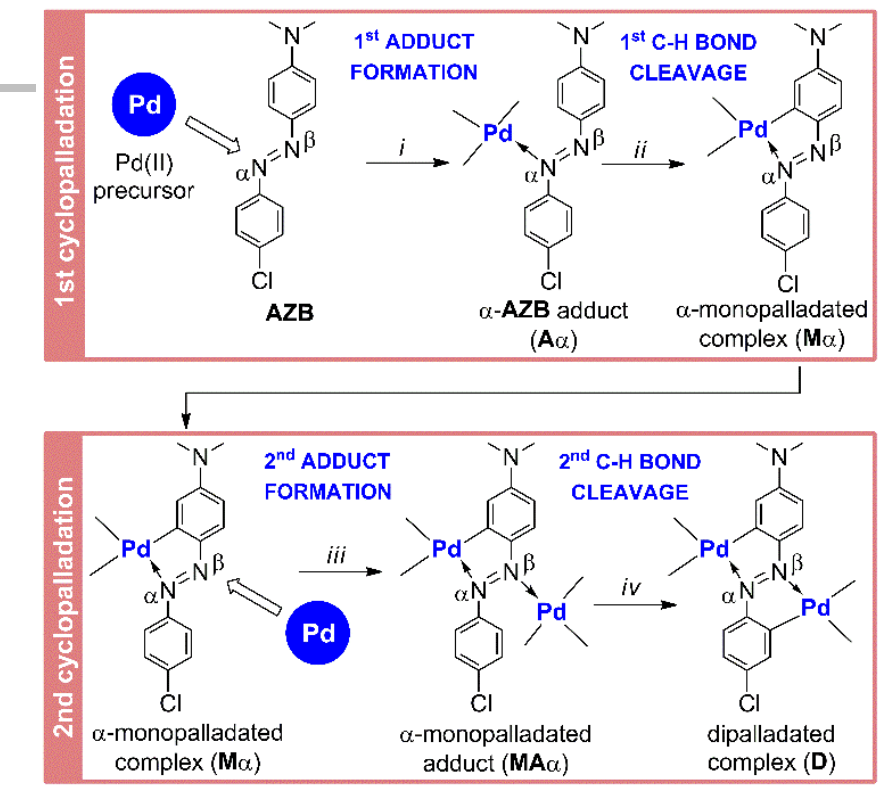

monomeric complex mD-I (Figure 2). Molecular structure (Figure S5) and the NMR data of the $\mathrm{mD}-\mathrm{I}$ product (Table S5) are analogous to other dicyclopalladated azobenzenes obtained from DMF solution. ${ }^{[5]}$

Ex situ PXRD monitoring of the solid-state reactions shows that amorphous mixtures (Figures SX-SY) are obtained by milling. Crystallinity of the product is restored by recrystallization in DMF. According to PXRD (Figure SX), two polymorphs of mDI can be isolated, but their solid-state Raman spectra are the same and exhibit two intensive bands at 1261 and $1289 \mathrm{~cm}^{-1}$ (Figure 2).

Isolation of intermediates. Studies of palladation of azobenzenes by $\mathrm{PdCl}_{2}{ }^{[14]}$ and $\mathrm{PdCl}_{2}(\mathrm{DMF})_{2}{ }^{[5]}$ a suggest that the mechanism of double palladation in solution consists of four successive steps (Scheme 1): (i) formation of the mononuclear adduct $A$ in which one azo-nitrogen is bound to the palladium; (ii) intramolecular $\mathrm{C}-\mathrm{H}$ bond activation resulting in the formation of a monopalladated intermediate $\mathrm{M}$; (iii) formation of a monopalladated adduct MA in which the free azo-nitrogen coordinates the second $\mathrm{Pd}$ precursor; and (iv) the second intramolecular $\mathrm{C}-\mathrm{H}$ bond activation producing a dipalladated product $\mathbf{D}$. Taking this into account, we have tried to obtain and analyze possible intermediates, i.e. the AZB adduct species, the monocyclopalladated complex and its adduct (Scheme 1). We note that all mentioned species could be monomeric (with terminal chlorides) or dimeric (with chlorides bridging two metal centers).

Spectroscopic data show that the first adduct and the monopalladated intermediates are formed in all studied milling reactions. Due to the rapid first palladation and the second palladation that starts shortly after the occurrence of the monopalladated product, these complexes could not be isolated from the bulk without impurities. Thus, we turned to reactions in solution.

The observed retarding effect of $\mathrm{MeCN}$ on palladation of $\mathbf{A Z B}$ was utilized to prepare the first intermediate, the AZB adduct, by reaction of $\mathrm{PdC}_{12}$ and $\mathrm{AZB}$ in MeCN solution. Single-crystal $\mathrm{X}$ ray analysis shows that the obtained product, $\mathbf{m A}_{\alpha}-\mathbf{I}$, is monomeric with Pd bound to alpha azo-nitrogen (Figures 2 and S2). ${ }^{1} \mathrm{H}$ NMR spectrum in $\mathrm{MeCN}-d_{3}$ contains four doublet signals of aromatic protons showing that only one isomer is present. 
The $\mathbf{m A}_{\alpha} \mathbf{I}$ is stable in MeCN solution but it partly isomerizes to $\mathbf{m A}_{\beta}-\mathbf{I}$ and dimerizes in $\mathrm{CDCl}_{3}$ in which up to a dozen species are observed by ${ }^{1} \mathrm{H}$ NMR (Figure S12). DMSO breaks all adducts and liberates AZB. Dimeric adducts could not be isolated.

Stirring of $\mathbf{m A}_{\boldsymbol{\alpha}} \mathbf{- I}$ in DMF after four days afforded a monomeric product with a palladated $p$-(N,N-dimethylamino)phenyl ring, $\mathbf{m M}_{\alpha}-\mathbf{I}$ (Figure 2) which was confirmed by single-crystal X-ray analysis (Figures S4). According to the single-crystal X-ray analysis (Figure S3), $\mathbf{m M}_{\alpha} \mathbf{- I}$ is monomeric in DMSO solution where $[\mathrm{PdCl}(\mathrm{AZB}-\mathrm{H})(\mathrm{DMSO})]$ is obtained by exchange of the coordinated DMF in $\mathbf{m M}_{\alpha}-\mathbf{I}$ with the DMSO solvent. Ex situ Raman spectrum of $\mathbf{m} \mathbf{M}_{\boldsymbol{\alpha}} \mathbf{I}$-I with bound DMF gives a strong band at $1323 \mathrm{~cm}^{-1}$ and two weaker bands at 1264 and $1295 \mathrm{~cm}^{-1}$ (Figure 2). In addition, a dimeric monocyclopalladated complex trans-[PdCl(AZB-H $)]_{2}, \mathbf{d M}-\mathbf{I}$, was prepared in methanol as a mixture of alpha and beta isomers in ca. 4:1 ratio with a small amount of the dipalladated complex (Figure S9). Its Raman spectrum shows bands at 1261 and $1289 \mathrm{~cm}^{-1}$ as well as broad bands at 1330 and $1590 \mathrm{~cm}^{-1}$ (Figure 2).

The third intermediate, the monopalladated adduct, could not be prepared either in solution or in solid state.

Monitoring of all reactions with chloride precursors and AZB by in situ Raman and ex situ NMR methods shows stepwise reaction pathways starting with the formation of adducts, followed by their transformation to the monopalladated species and further to the dipalladated product. Reactions with $\mathrm{PdCl}_{2}$ gave nicely resolved Raman data with gradual interchange between the observed species that allowed extraction of the reaction profiles (Figure 3). Reaction mixtures with $\mathrm{PdCl}_{2}(\mathrm{MeCN})_{2}$ contained a large amount of liquid (e.g. DMF $\mathrm{MeCN}$ and/or $\mathrm{AcOH}$ ) which induced partial sticking of the mixture to jar walls. The best data for the $\mathrm{PdCl}_{2}(\mathrm{MeCN})_{2}$ reactions, obtained for the ILAG-DMF/PdCl $(\mathrm{MeCN})_{2}$, confirms the analogous reaction course as in the $\mathrm{PdCl}_{2}$ reactions (Figure S37).

Complete transformation of AZB to the chloride dipalladated product in ILAG-AcOH/PdCl 2 was confirmed by ${ }^{1} \mathrm{H}$ NMR after 8 hours of milling. Raman data suggested unrealistically faster reaction due to parallel occurrence of chloride and acetate palladated complexes which show highly similar Raman spectra Therefore, Raman analysis was not used for the ILAG$\mathrm{AcOH} / \mathrm{PdCl}_{2}$.

Occurrence of the adduct in all reactions of chloride precursors and AZB is followed by intensity decrease of the $v(\mathrm{Pd}-\mathrm{Cl})$ band of $\mathrm{PdCl}_{2}$ located at $278 \mathrm{~cm}^{-1}$ as well as change in $v(\mathrm{~N}=\mathrm{N}), v(\mathrm{C}-$ $\left.\mathrm{N}_{\mathrm{azo}}\right)_{\mathrm{NMe} 2}$ and $v\left(\mathrm{C}-\mathrm{N}_{\mathrm{azo}}\right)_{\mathrm{Cl}}$ bands in $1100-1650 \mathrm{~cm}^{-1}$ range. Apart from small shifts of bands about $1400 \mathrm{~cm}^{-1}$ which contain $v(\mathrm{~N}=\mathrm{N})$ contribution, a band at $1137 \mathrm{~cm}^{-1}$ in AZB originating from stretching of both $\mathrm{C}-\mathrm{N}_{\mathrm{azo}}$ bonds is shifted to $1153 \mathrm{~cm}^{-1}$ in the adduct (Figure 3 ). Changes suggest perturbation about the $\mathrm{C}$ $\mathrm{N}=\mathrm{N}-\mathrm{C}$ fragment of $\mathbf{A Z B}$ supporting the coordination of the azonitrogen to Pd.

Transformation of the adduct into the monopalladated species results in a large shift of the bands with $\mathrm{v}(\mathrm{N}=\mathrm{N})$ contribution from 1415,1398 and $1371 \mathrm{~cm}^{-1}$ in the adduct to $1289 \mathrm{~cm}^{-1}$ in dM-I.
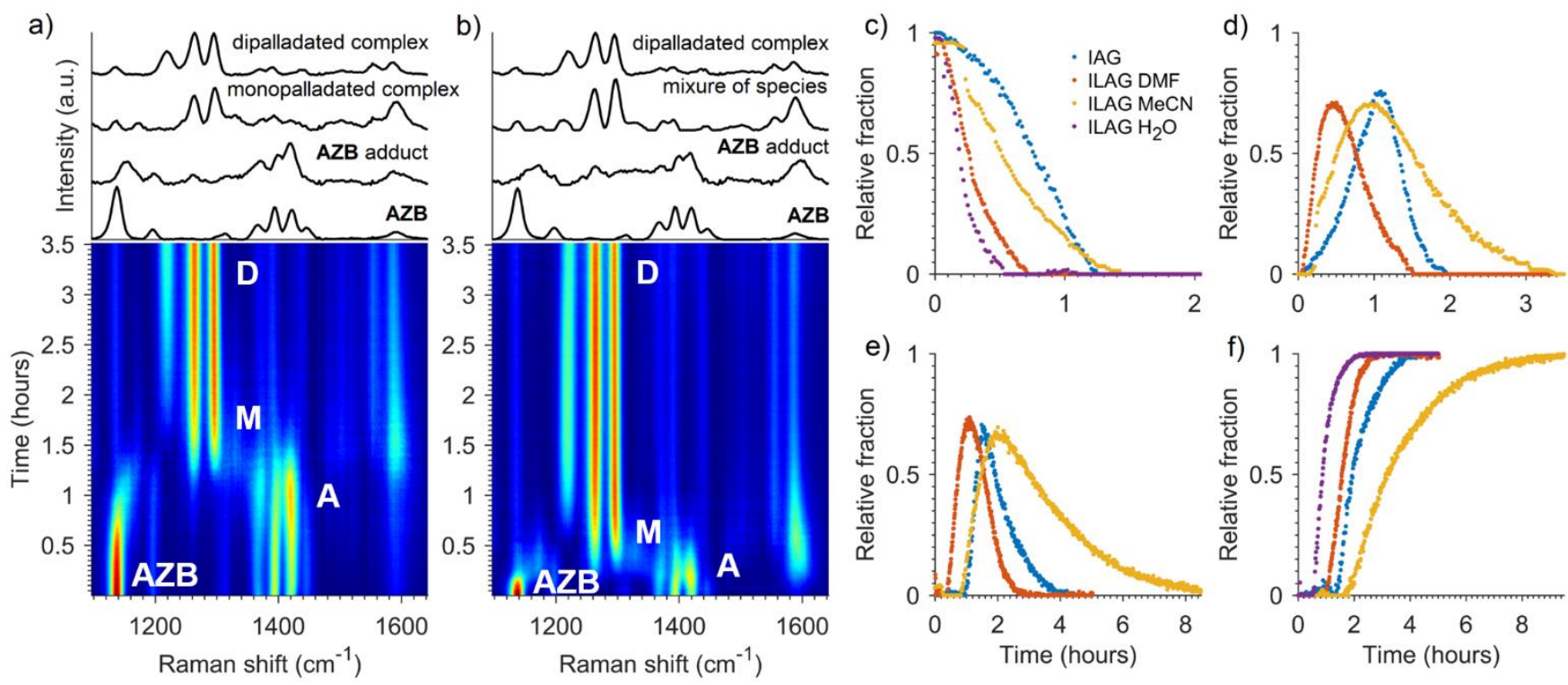

Figure 3. Time-resolved monitoring of dipalladation of AZB by $\mathrm{PdCl}_{2}$ under a) IAG and b) ILAG- $\mathrm{H}_{2} \mathrm{O}$ reaction conditions. Re-action profiles derived from multivariate curve analysis - alternate least squares (MCR-ALS) for c) AZB, d) the adduct, e) the monopalladated and f) the dipalladated species. Spectra derived from MCR-ALS are above 2D time-resolved spectra in a) and b). Spectra that should represent adduct and monopalladated species in b) are linear combinations of their pure contributions because of their concurrent occurrence during milling. This resulted in poor modeling and poor reaction profiles that are not shown 
Stretching of the $\left(\mathrm{C}-\mathrm{N}_{\mathrm{azo}}\right) \mathrm{NMe}_{2}$ bond contributes to the band at $1153 \mathrm{~cm}^{-1}$ in the adduct and $1264 \mathrm{~cm}^{-1}$ in the monopalladated species. The $v\left(C-N_{a z o}\right) N_{2}$ band shift to higher and $v(N=N)$ bands to lower energies is accompanied by shortening and elongation of $\left(\mathrm{C}-\mathrm{N}_{\mathrm{azo}}\right) \mathrm{NMe}_{2}$ and $\mathrm{N}=\mathrm{N}$ bonds, respectively. These observations are connected with structural changes induced by formation a delocalized five-membered palladacycle after the first palladation on the phenyl ring with the electron-donating substituent (Table S2). Raman monitoring shows that the monomeric complex $\mathbf{m M}_{\alpha}-\mathbf{I}$ with a coordinated DMF used as the liquid additive is not observed in the studied ILAG-DMF reactions indicating that all reactions proceed via dimeric monopalladated intermediates. In addition, ex situ ${ }^{1} \mathrm{H}$ NMR detected only a minute amount of the beta monopalladated complex in the reaction mixtures showing that the reaction mostly runs via the alpha route (Scheme 1).

Hereafter, the second palladation on the chlorophenyl ring occurs and results in a dipalladated product (Figure 3). The monopalladated adduct(s) MA-I (Scheme 1) should be formed from the monopalladated species and might show Raman spectrum similar to the parent dM-I. Taking into account failed attempts to prepare MA-I and ex situ NMR data that suggests only a small amount of MA-I in the reaction mixtures (Figure S16), the observed bands at 1264 and $1292 \mathrm{~cm}^{-1}$ could be assigned to $\mathbf{d M}$-I rather than MA-I. Moreover, Raman analysis (Figure 3) and ${ }^{1} \mathrm{H}$ NMR monitoring (Figure SX) show that dipalladation of AZB by both chloride precursors starts shortly after the monopalladated complex is formed.

The dipalladated crude products from all studied reactions show three intensive Raman bands at 1220,1261 and $1289 \mathrm{~cm}^{-1}$ (Figure 3 ) in contrast to only two bands of the isolated complex mD-I (Figure 2). Further experiments have shown that the 1220 $\mathrm{cm}^{-1}$ band is retained after washing the crude product with $\mathrm{H}_{2} \mathrm{O}$ and acetone, but is lost if the crude product is recrystallized from DMF or kept in DMF vapor. Other two bands at 1261 and 1289 $\mathrm{cm}^{-1}$ remain unchanged. Taking into account the spectroscopic analysis of the washed products that agrees with composition of the solid being $\left[\mathrm{Pd}_{2} \mathrm{Cl}_{2}(\mathrm{AZB}-2 \mathrm{H})\right]$, we propose formation of a coordinately-unsaturated, dimeric or polymeric, product during milling that gives the monomeric complex mD-I after recrystallization in DMF solution.

Mechanism. Rate of transformation of AZB into the first adducts increases in the following order of additives: none $<\mathrm{MeCN}<$ DMF $<\mathrm{H}_{2} \mathrm{O}$ indicating that the listed liquids assist the formation of the first intermediate (Figure 3 ). Either adducts with monomeric $\left[\mathrm{PdCl}_{2}(\mathbf{A Z B})\right.$ (Solvent)], i.e. $\mathbf{m A}_{\alpha}-\mathbf{I}$ and $\mathbf{m A}_{\beta}-\mathbf{I}$, or dimeric structure $\left[\mathrm{PdCl}_{2}(\mathbf{A Z B})\right]_{2}$, e.g. cis- $\left(\mathbf{d A}_{\alpha}-\mathbf{I}\right)$ and trans- $\left(\mathbf{d A}_{\alpha}-\right.$ I), are expected (Figure 4). ${ }^{[2 b, 13]}$ Differentiating monomeric from dimeric adducts in situ by Raman spectroscopy is not feasible as their spectra, according to calculations, should show only minor differences (Figures S53 and S54). Thus, a detailed IR and

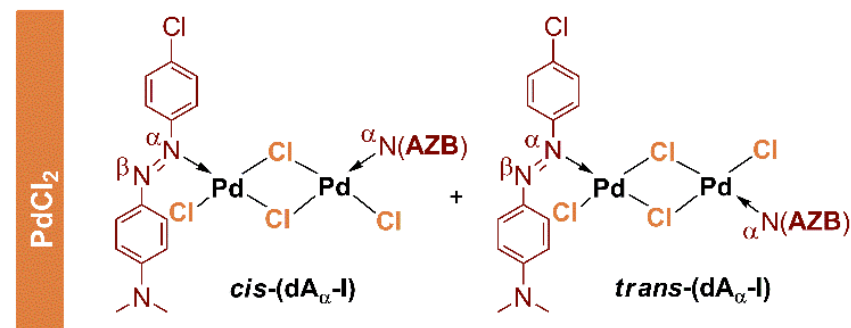

other isomers are possible (e.g. anti/syn orientation of substituents on AZB, or bonding to alpha/beta nitrogen atoms)
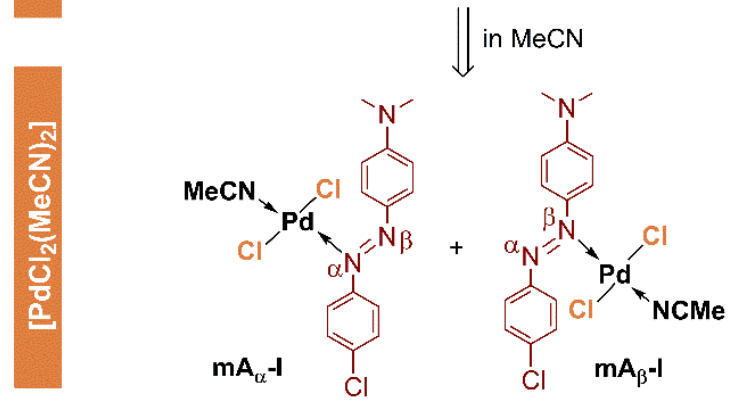

NMR spectral analysis was necessary to gain important data on possible isomerism during milling and possible ancillary ligands bound to Pd centers. ${ }^{1} \mathrm{H}$ NMR spectra of all reaction mixtures with chloride precursors after 15-45 minutes of milling show multiple sets of signals, typical for coordination complexes of aminoazobenzenes, ${ }^{[13]}$ due to presence of monomeric or dimeric

Figure 4. The first AZB adduct intermediates formed in reactions with chloride precursors.

alpha or beta isomers containing Pd bound to alpha or beta azonitrogen (Figure S14). According to the previous studies of azobenzene palladation, ${ }^{[13]}$ alpha isomers should be dominant over beta isomers. ${ }^{1} \mathrm{H}$ NMR (Figure S14) and IR (Figure S22) spectra of the $\mathrm{PdCl}_{2}(\mathrm{MeCN})_{2}$ reaction mixtures reveal that the isolated $\mathbf{m A}_{\boldsymbol{\alpha}}-\mathbf{I}$ and its beta isomer $\mathbf{m A}_{\boldsymbol{\beta}}-\mathbf{I}$ are dominant adducts in both $\mathrm{PdCl}_{2}(\mathrm{MeCN})_{2}$ reactions (Figure 4 and $\left.\mathrm{S} 14\right)$. In contrast, $\mathrm{PdCl}_{2}$ reactions progress mostly via dimeric adducts. In addition, ${ }^{1} \mathrm{H}$ NMR of the ILAG-MeCN/ $/ \mathrm{CCl}_{2}$ reaction mixture after 45 minutes of milling shows both types of adducts with the dominant dimeric species in the mixture (Figure S14). We note that despite a large excess of chloride precursors, spectroscopic data suggests that double adducts $\left[\mathrm{Pd}_{2} \mathrm{Cl}_{4}(\mathrm{AZB})(\mathrm{MeCN})_{2}\right]$, which would have one $\mathrm{Pd}$ center at each azo-nitrogen, are not observed. For these complexes, $v(\mathrm{~N}=\mathrm{N})$ Raman band(s) should be located between $v(\mathrm{~N}=\mathrm{N})$ bands of $\mathrm{mA}_{\alpha}-\mathbf{I}$ and the monopalladated species due to coordination of the second $\mathrm{Pd}$ at free azo-nitrogen which would further weaken the azo bond, but this was not observed. 
In the $\mathrm{IAG} / \mathrm{PdCl} \mathrm{I}_{2}$ reaction, the adduct formation is slow and the monopalladated species occurs after ca. 50 minutes of milling (Figure $3 \mathrm{e}$, blue). The monopalladated intermediate forms after only 20 minutes of milling in ILAG-DMF/ $\mathrm{PdCl}_{2}$ (Figure 3e, red) and 50 minutes for ILAG-MeCN/PdCl 2 (Figure 3e, yellow). The dipalladated complex appears after 30 minutes in ILAG$\mathrm{H}_{2} \mathrm{O} / \mathrm{PdCl}_{2}$ (Figure $3 f$, violet) whereas in $\mathrm{IAG} / \mathrm{PdCl}_{2}$ (Figure $3 f$, blue) and ILAG-DMF/PdCl 2 (Figure $3 f$, red) it is observed after ca. 80 and 60 minutes, respectively. The second palladation is the slowest for ILAG-MeCN/PdCl 2 and starts after about 110 minutes of milling (Figure $3 f$, yellow). This slow reaction could be attributed to detrimental action of $\mathrm{MeCN}$ onto palladation observed also in solution and/or lower reactivity of monomeric adducts which are present in ILAG-MeCN/PdCl ${ }_{2}$ and dominant in $\mathrm{PdCl}_{2}(\mathrm{MeCN})_{2}$ reactions.

Reaction times needed for the complete conversion of AZB to the dipalladated product increase in the following order: IAG/PdCl 2 (4.5 h, Table 1) < ILAG-MeCN/PdCl 2 (11 h) < IAG/PdCl $2(\mathrm{MeCN})_{2}(15 \mathrm{~h})<\mathrm{ILAG}-\mathrm{MeCN} / \mathrm{PdCl}_{2}(\mathrm{MeCN})_{2}(20 \mathrm{~h})$. Apart from different adducts (Figure 4), this effect can be rationalized by partial formation of $\mathrm{PdCl}_{2}(\mathrm{MeCN})_{2}$ from $\mathrm{PdCl}_{2}$ and $\mathrm{MeCN}$. This side reaction was independently confirmed by LAG-MeCN of $\mathrm{PdCl}_{2}$ (Figure S25). Much slower IAG/PdCl $2(\mathrm{MeCN})_{2}$ than ILAG-MeCN/PdCl 2 , can be attributed to $\mathrm{MeCN}$ released by formation of the first intermediates, monomeric alpha and beta adducts $\left[\mathrm{PdCl}_{2}(\mathbf{A Z B})(\mathrm{MeCN})\right]$, in IAG/ $\mathrm{PdCl}_{2}(\mathrm{MeCN})_{2}$. Namely, this process liberates one equivalent of MeCN (ca. $13 \mu \mathrm{L}$ ) per equivalent of the precursor to the bulk. The released $\mathrm{MeCN}$ retards the $\mathrm{PdCl}_{2}(\mathrm{MeCN})_{2}$ reactions if compared to the $\mathrm{PdCl}_{2}$ processes (Table 1 ). Additional MeCN introduced in the ILAG-MeCN/PdCl $(\mathrm{MeCN})_{2}$ slows the palladation even more extending the reaction to 20 hours.

Taking into account the clear in situ observation of the adducts as well as the acceleration effect of DMF or $\mathrm{H}_{2} \mathrm{O}$ that both enable the $\mathrm{C}-\mathrm{H}$ bond cleavage by facilitating proton elimination, whereas $\mathrm{MeCN}$ addition retards the reaction, breaking of the $\mathrm{C}$ $\mathrm{H}$ bond is most likely the slow step in the solid-state palladation by $\mathrm{PdCl}_{2}$. This agrees with the studies in solution and calculations (Scheme 1). ${ }^{[5 a, 14]}$ Observed rates for the $\mathrm{C}-\mathrm{H}$ bond cleavage could be related to the basicity of the employed additives which according to Gutmann's scale ${ }^{[15]}$ increases in order: $\mathrm{MeCN}<\mathrm{H}_{2} \mathrm{O}<\mathrm{DMF}$. Moreover, the second palladation in both, IAG and ILAG, is slower than the first (Figure 3), as in solution, ${ }^{[5 a]}$ but its slow step could not be definitely identified as we could not prepare the monocyclopalladated adduct. We note that $\mathrm{AcOH}$, released as a byproduct during the first palladation, could possibly hinder the second palladation as the cleavage of the $\mathrm{C}-\mathrm{H}$ bond releases a proton and might be decelerated in more acidic environment.

Finally, after considering both chloride precursors, the polymeric neutral $\mathrm{PdCl}_{2}$ proved as a better choice than the monomeric precursor $\mathrm{PdCl}_{2}(\mathrm{MeCN})_{2}$ for the solid-state activation of the $\mathrm{C}-\mathrm{H}$ bonds. $\mathrm{PdCl}_{2}(\mathrm{MeCN})_{2}$ introduces a large amount of $\mathrm{MeCN}$ to the reaction mixture which slows down the reaction. A "green" liquid, $\mathrm{H}_{2} \mathrm{O}$, is identified as the best liquid additive. It
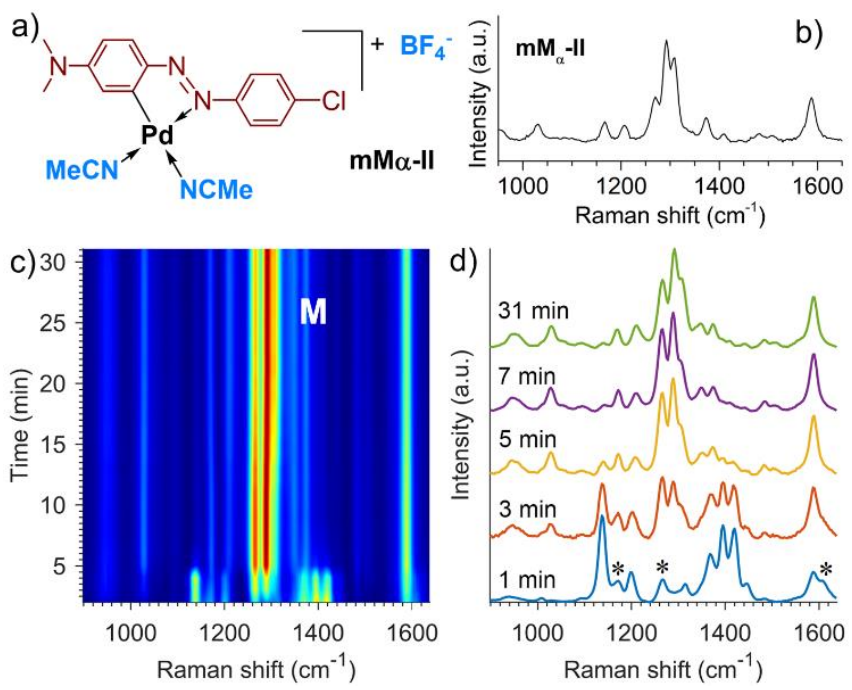

facilitates the solid-state palladation and allows formation of the product that is free of harmful organic solvents.

\section{Reactions with precursor II - $\left[\mathrm{Pd}(\mathrm{MeCN})_{4}\right]\left[\mathrm{BF}_{4}\right]_{2}$}

Milling experiments. IAG of $\left[\mathrm{Pd}(\mathrm{MeCN})_{4}\right]\left[\mathrm{BF}_{4}\right]_{2}$ and $\mathbf{A Z B}$ in a $1: 1$ molar ratio with one equivalent of $\mathrm{NaOAc}$ and one equivalent of $\mathrm{NaBF}_{4}$ as additives resulted in a homogeneous monopalladated product $\mathbf{m M}_{\boldsymbol{\alpha}}-\boldsymbol{I l}$ within 25 minutes of milling (Figure 5a). NaOAc was added to prevent a reverse reaction promoted by release of a strong tetrafluoroboric acid and to act as external base that accepts a proton released during cyclopalladation. The presence of $\mathrm{AcOH}$ was confirmed by ${ }^{1} \mathrm{H}$ NMR spectra of the bulk mixture. Use of $\mathrm{NaBF}_{4}$ acted beneficial in two ways, first by enabling mechanochemical reactions between $\left[\mathrm{Pd}(\mathrm{MeCN})_{4}\right]\left[\mathrm{BF}_{4}\right]_{2}$ and

Figure 5. a) Structure of the monomeric alpha monopalladated AZB complex of the precursor II, i.e. $\left[\mathrm{Pd}(\mathrm{AZB}-\mathrm{H})(\mathrm{MeCN})_{2}\right]\left[\mathrm{BF}_{4}\right],\left(\mathrm{mM}_{-}-\mathrm{II}\right)$; b) normalized solid-state Raman spectrum of $\mathrm{mM}_{-}-\mathrm{Il}$; c) $2 \mathrm{D}$ plot of time-resolved Raman monitoring of IAG of $A Z B$ and $\left[\mathrm{Pd}(\mathrm{MeCN})_{4}\right]\left[\mathrm{BF}_{4}\right]_{2}$; and d) part of the Raman spectra at selected times showing tentative signals of the adduct marked with an asterisk $\left(^{*}\right)$

AZB which failed under NG, LAG-DMF and ILAG-DMF conditions due to large amount of present liquids released during reaction, and second, by preventing the formation of an acetate monopalladated complex that occurred during milling with an excess of $\mathrm{NaOAc}$. We note that excess of $\mathrm{NaBF}_{4}$ without $\mathrm{NaOAc}$ resulted in an incomplete conversion of AZB to $\mathbf{m M}_{\boldsymbol{\alpha}}-\mathbf{I I}$.

Product isolation and identification. Single-crystal $X$-ray analysis of $\mathbf{m M}_{\boldsymbol{\alpha}}$-II confirmed that the palladation occurred at the 4-(N,N-dimethylamino)phenyl ring and that two MeCN ligands are coordinated to $\mathrm{Pd}$ (Figures $5 \mathrm{a}$ and S6). The $\mathbf{m M}_{\alpha}$-II gives intensive bands at 1270, 1292 and $1306 \mathrm{~cm}^{-1}$ in the Raman spectrum (Figure $5 b$ ). Ex situ PXRD monitoring during milling of AZB and $\left[\mathrm{Pd}(\mathrm{MeCN})_{4}\right]\left[\mathrm{BF}_{4}\right]_{2}$ revealed that the reactants retain crystallinity and produce a crystalline product $\mathbf{m M}_{\alpha}-\mathrm{Il}$ (Figure S44). We note that $\mathbf{m M}_{\alpha}-$ Il could not be isolated in solution. All 
attempts to prepare the first adduct intermediate failed due to the rapid conversion of AZB to $\mathbf{m M}_{\boldsymbol{\alpha}}-\mathrm{II}$.

Formation of a dipalladated complex directly from $\mathbf{A Z B}$ and $\left[\mathrm{Pd}\left(\mathrm{CH}_{3} \mathrm{CN}\right)_{4}\right]\left[\mathrm{BF}_{4}\right]_{2}$ or from the purified product $\mathbf{m M}_{\alpha}-\mathrm{II}$, with $\mathrm{NaOAc}$ and $\mathrm{NaBF}_{4}$ as additives, was not achieved since both reaction mixtures contained a large amount of released liquids and got stuck to the milling ball after five minutes of milling which terminated the reaction.

Monitoring and mechanism. In situ Raman monitoring demonstrated that IAG of $\left[\mathrm{Pd}(\mathrm{MeCN})_{4}\right]\left[\mathrm{BF}_{4}\right]_{2}$ and $\mathbf{A Z B}$ in a $1: 1$ molar ratio rapidly yields $\mathbf{m M}_{\alpha}-$ II (Figure $5 \mathrm{c}$ ). Formation of the mononuclear adduct might be proposed upon close inspection of the Raman spectra. Apart from AZB bands, at least three additional low-intensity bands at 1172, 1267 and $1609 \mathrm{~cm}^{-1}$ are observed after one minute of milling (Figure $5 \mathrm{~d}$ ). In addition, ${ }^{1} \mathrm{H}$ spectrum of the reaction mixture in $\mathrm{MeCN}-d_{3}$ after one minute of milling contains two sets of low-intensity doublets in ca. 2:1 ratio as well as strong signals of AZB and weak signals of $\mathbf{m M}_{\alpha}-\mathrm{II}$ (Figure S17). This supports formation of $\mathbf{m A}_{\alpha}-$ II and $\mathbf{m} \mathbf{A}_{\beta}$-II. Next step, the $\mathrm{C}-\mathrm{H}$ bond cleavage, is regioselective. $\mathbf{m M}_{\alpha}-\mathrm{Il}$ and traces of its beta isomer $\mathbf{m M}_{\boldsymbol{\beta}}$-ll are obtained, according to ${ }^{1} \mathrm{H}$ NMR, which indicates that two adducts are in equilibrium and the reaction favors the alpha route toward $\mathbf{m M}_{\alpha}-$ II.

Results reveal high reactivity of the ionic precursor that rapidly coordinates at azo-nitrogen of AZB and the formed adduct readily transforms to the monopalladated product (Figure $5 \mathrm{c}$ ). Similar to the reactions of the chloride precursors, observation of the adducts suggests that the $\mathrm{C}-\mathrm{H}$ bond activation is slower than the adduct formation.

\section{Reactions with precursor III - $\left[\mathrm{Pd}(\mathrm{OAc})_{2}\right]_{3}$}

Milling experiments. NG reaction of $\left[\mathrm{Pd}(\mathrm{OAc})_{2}\right]_{3}$ and $\mathbf{A Z B}$ in a 1:3 molar ratio was extremely slow taking 50 hours to completion (Table 2). Further we followed the synthetic procedure developed recently by our group ${ }^{[11]}$ and performed LAG palladation of AZB by $\left[\mathrm{Pd}(\mathrm{OAc})_{2}\right]_{3}$ in a $3: 1$ molar ratio that afforded a dimeric monopalladated product $\mathbf{d M}_{\alpha}$-III (Figure 6). Effect of liquid additives was tested using DMF, MeCN, $\mathrm{AcOH}$ or $\mathrm{H}_{2} \mathrm{O}$. Reaction times for the synthesis of $\mathbf{d M}_{\alpha}-$ III with the employed liquids increase in the following order: DMF $<\mathrm{H}_{2} \mathrm{O}<$ $\mathrm{MeCN}<\mathrm{AcOH}<$ none (Table 2). Analogous ILAG processes in which one equivalent of $\mathrm{NaOAc}$ is added are slow and result in $\mathbf{d M}_{\alpha}-$ III in $20 \mathrm{~h}$ (ILAG- $\left.\mathrm{H}_{2} \mathrm{O}\right)$ and $30 \mathrm{~h}$ (ILAG-AcOH). ILAG-DMF reaction afforded a mixture of precursors and $\mathbf{d M}_{\alpha}$-III even after 50 hours of milling. This could be related to the formation of various $\mathrm{Pd}$ acetate species that retard the reaction.

Table 2. LAG palladation of AZB by $\left[\mathrm{Pd}(\mathrm{OAc})_{2}\right]_{3}$

\begin{tabular}{lclll}
\hline No. & {$\left[\mathrm{Pd}(\mathrm{OAc})_{2}\right]_{3}: \mathbf{A Z B}$} & Product & Liquid & Time $^{*} / \mathrm{h}$ \\
\hline 1 & $1: 3$ & $\mathbf{d M}_{\alpha}$-III & - & 50 \\
2 & $1: 3$ & $\mathbf{d M}_{\alpha}$-III & DMF & 7 \\
3 & $1: 3$ & $\mathbf{d M}_{\alpha}-$ III & $\mathrm{H}_{2} \mathrm{O}$ & 8
\end{tabular}

$\begin{array}{lllll}4 & 1: 3 & \mathbf{d M}_{\alpha}-\text { III } & \mathrm{MeCN} & 15 \\ 5 & 1: 3 & \mathbf{d M}_{\alpha}-\text { III } & \text { AcOH } & 30 \\ 6 & 2: 3 & \mathbf{d D}-\text { III } & \text { DMF } & 21 \\ 7 & 2: 3 & \mathbf{d D}-\text { III } & \mathrm{H}_{2} \mathrm{O} & 22 \\ 8 & 4: 3 & \mathbf{d M}_{\alpha}-\text { III } & \mathrm{H}_{2} \mathrm{O} & 3.5\end{array}$

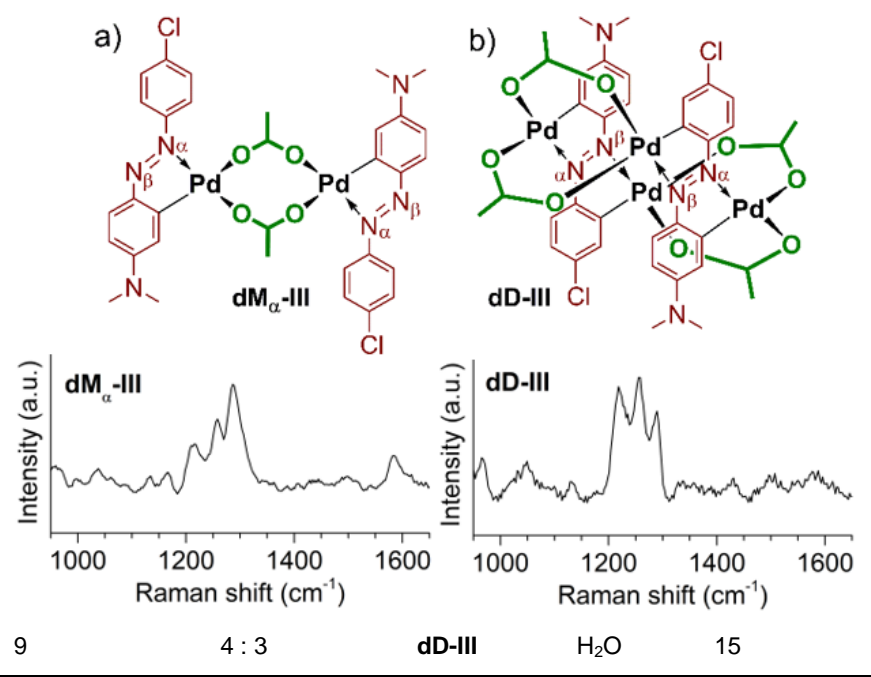

* Corresponds to time at which full conversion to an acetate palladated product is confirmed by NMR and Raman.

The dipalladated product dD-III (Figure 6) is obtained by LAG of $\mathbf{A Z B}$ and $\left[\mathrm{Pd}(\mathrm{OAc})_{2}\right]_{3}$ in a 2:3 molar ratio in about 22 hours which

Figure 6. Structures and selected part of normalized solid-state Raman spectra of AZB complexes of the precursor III: a) monopalladated product $[\mathrm{Pd}(\mu-\mathrm{OAC})(\mathbf{A Z B}-\mathrm{H})]_{2} \quad\left(\mathbf{d M}_{\alpha}-\mathrm{III}\right)$ and $\quad$ b) dipalladated product $[\mathrm{Pd} 2(\mu-$ OAc)2(AZB-2H) $]_{2}$ (dD-III).

shows that the second palladation is slower than the first (Table 2). We note that the all solid-state syntheses of both acetate complexes, $\mathbf{d M}_{\alpha}-$ III and $\mathbf{d D}$-III are considerably faster and cleaner than reaction in DMF solution that takes about one and three weeks, respectively.

LAG- $\mathrm{H}_{2} \mathrm{O}$ of $\left[\mathrm{Pd}(\mathrm{OAc})_{2}\right]_{3}$ and AZB in a $4: 3$ molar ratio has been conducted for comparison with the solid-state palladation by the chloride precursors. The mono- and dipalladated products, $\mathbf{d M}_{\alpha}$-III and $\mathbf{d D}$-III, are obtained after 3.5 and 15 hours demonstrating that the reaction is slower than with the chloride precursors. In addition, isolation of the products is difficult due to similar solubility of the acetate products and the precursor. Thus, using $\left[\mathrm{Pd}(\mathrm{OAc})_{2}\right]_{3}$ in a stoichiometric excess is not a feasible synthetic approach to the acetate azobenzene complexes

Product isolation and identification. Structures of $\mathbf{d M}_{\alpha}-\mathrm{III}$ and dD-III, resolved by single-crystal X-ray diffraction (Figures S7 and S8) and supported by spectroscopic data, are analogous to recently reported structures of mono- and dipalladated 4'-(N,Ndimethylamino)-4- nitroazobenzenes. ${ }^{[11]} \mathbf{d M}_{\alpha}$-III and $\mathbf{d D}$-III are 
dimers which adopt an open- and a closed-book structure, respectively.

Both acetate complexes, $\mathbf{d M}_{\alpha}-$ III and $\mathbf{d D}$-III, recrystallized from $\mathrm{CHCl}_{3}$ give Raman bands at 1215, 1258 and $1289 \mathrm{~cm}^{-1}$ but with different intensities (Figure 6). Analogous to complexes of other precursors and literature data ${ }^{11}$, intensive bands of the acetate complexes at ca. 1260 and $1290 \mathrm{~cm}^{-1}$ contain contributions of vibrations including $\mathrm{N}=\mathrm{N}$ and $\left(\mathrm{C}-\mathrm{N}_{\mathrm{azo}}\right)_{\mathrm{NMe}}$ bonds.
Isolation of intermediates. All attempts to prepare any coordination complex of $\left[\mathrm{Pd}(\mathrm{OAc})_{2}\right]_{3}$ with AZB or dM-III by reactions in solution ( $\mathrm{MeCN}, \mathrm{CH}_{2} \mathrm{Cl}_{2}$, DMF, acetone, toluene) or in the solid state failed. Moreover, ${ }^{1} \mathrm{H}$ NMR spectra of all obtained mixtures in $\mathrm{CDCl}_{3}$ or $\mathrm{MeCN}-d_{3}$ show only signals of AZB, mono- and dipalladated products. 

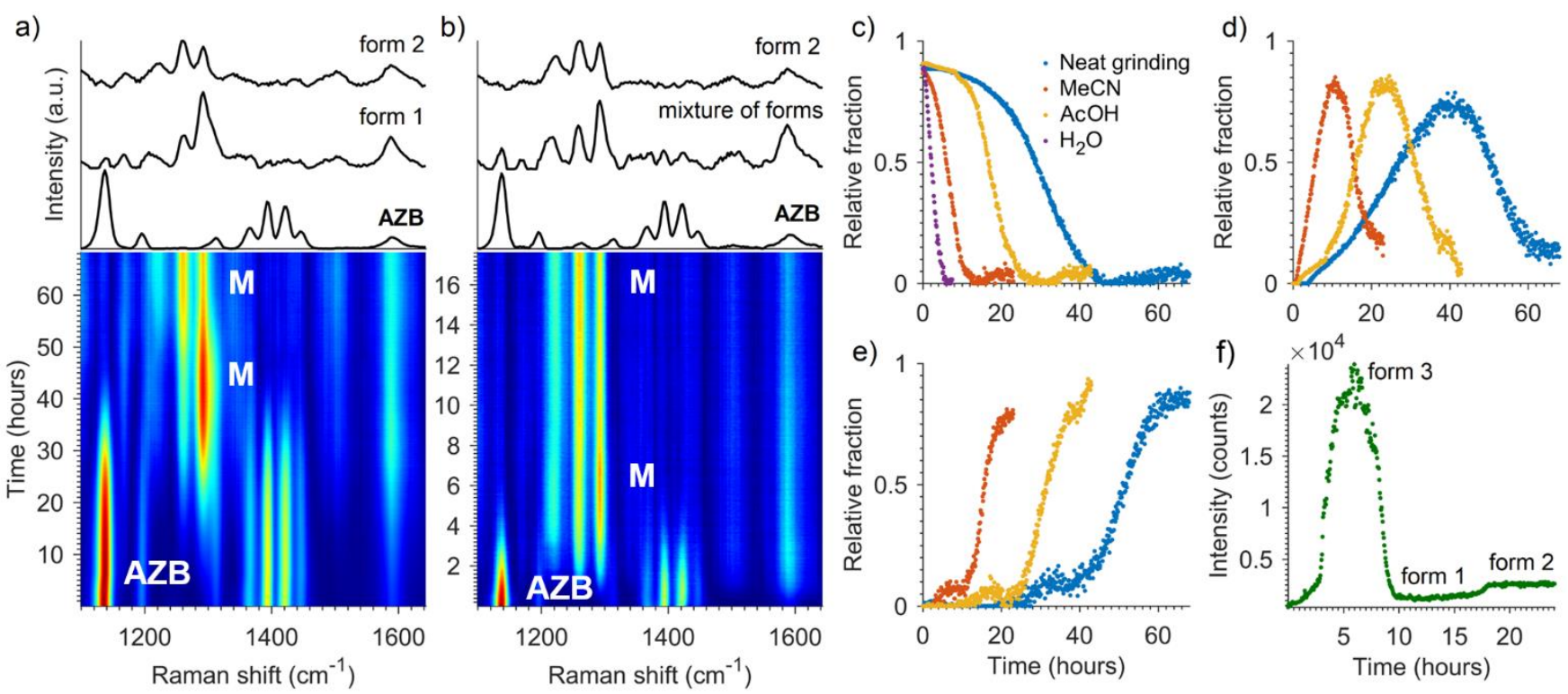

Figure 7. Time-resolved monitoring of monopalladation of AZB by $\left[\mathrm{Pd}(\mathrm{OAc})_{2}\right]_{3}$ under a) $\mathrm{NG}$ and b) LAG- $\mathrm{H}_{2} \mathrm{O}$ reaction conditions. Above $2 \mathrm{D}$ plots are spectra contributions obtained from MCR-ALS analysis. Spectrum for the second contribution in $\mathrm{LAG}-\mathrm{H}_{2} \mathrm{O}$ represents mixed spectra of forms due to inability to resolve pure contributions. Reaction profiles obtained from MCR-ALS analysis of c) AZB, d) the monopalladated form 1 and e) the monopalladated form 2; and f) LAGDMF fluorescence at $1700 \mathrm{~cm}^{-1}$

Monitoring. In situ results show that the $\mathrm{C}-\mathrm{H}$ bond activation with $\left[\mathrm{Pd}(\mathrm{OAc})_{2}\right]_{3}$ is significantly slower with respect to other tested $\mathrm{Pd}(\mathrm{II})$ precursors. Raman data for LAG reactions of $\left[\mathrm{Pd}(\mathrm{OAC})_{2}\right]_{3}$ and $\mathbf{A Z B}$ in molar ratio $1: 3$ reveal slow transformation of $\mathbf{A Z B}$ to the monopalladated complex (Figure 7). Consummation of the precursor during the studied NG and LAG reactions is also evident from $v(\mathrm{Pd}-\mathrm{O})$ Raman band at $339 \mathrm{~cm}^{-1}$ that loses intensity simultaneously with AZB bands. Adducts were not observed. $\mathrm{AcOH}$ was detected by ${ }^{1} \mathrm{H} \mathrm{NMR}$ in all reaction mixtures showing that the acetate collects the eliminated proton.

Three solid-state forms of $\mathbf{d M}_{\alpha}-$ III were observed during milling of $\mathbf{A Z B}$ and $\left[\mathrm{Pd}(\mathrm{OAc})_{2}\right]_{3}$. The form 1 of $\mathbf{d M}_{\alpha}-\mathbf{I I I}$ is obtained in all reactions and shows two Raman bands at 1261 and $1292 \mathrm{~cm}^{-1}$. During milling the form 1 gradually transforms to the form 2 (Figure 7). The form 2 is the final form of $\mathbf{d M}_{\alpha}$-III that occurs during milling and is characterized by bands at 1218, 1259 and $1292 \mathrm{~cm}^{-1}$. The third form of $\mathbf{d M}_{\alpha}$-III (form 3), exclusively observed in LAG-DMF is characterized by strong Raman bands at 1207,1255 and $1289 \mathrm{~cm}^{-1}$ and is highly fluorescent in the solid state (Figures $7 f$ and S43). This form of $\mathbf{d M}_{\alpha}$-III could not be characterized in detail as washing of the reaction mixture or aging in air induced a change to the form 1. All forms display the same properties in solution and their spectroscopic data are consistent with the monopalladated acetate complex.

Results show that the second palladation of AZB by $\left[\mathrm{Pd}(\mathrm{OAc})_{2}\right]_{3}$ is considerably slower than the first palladation. Monitoring revealed that the LAG of $\left[\mathrm{Pd}(\mathrm{OAc})_{2}\right]_{3}$ and AZB in molar ratio $2: 3$ is a stepwise reaction in which $\mathbf{d D}$-III is formed via $\mathbf{d M}_{\alpha}-$ III. Moreover, according to ${ }^{1} \mathrm{H}$ NMR, the second palladation of $\mathbf{A Z B}$ by $\left[\mathrm{Pd}(\mathrm{OAc})_{2}\right]_{3}$ occurs after $\mathbf{A Z B}$ is mostly transformed into $\mathbf{d M}_{\alpha}$-III which is in strong contrast to palladation by the chloride precursors for which the second palladation occurs shortly after the occurrence of the monopalladated complex. Raman spectra of $\mathbf{d M}_{\boldsymbol{\alpha}}$-III and $\mathbf{d D}$-III contain characteristic bands that are mostly overlapping which prevented more detailed analysis of the second palladation by Raman spectroscopy.

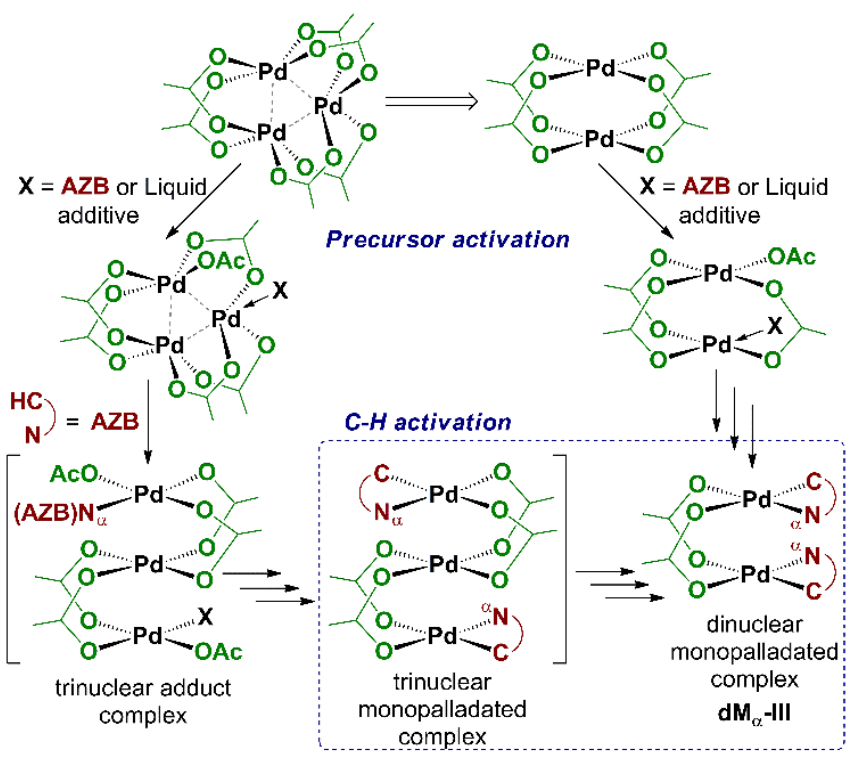

Many isomers and mixed species are possible

(i.e. AZB-Liquid additive and/or adduct-monopalladated species)

Scheme 2. Proposed mechanism of the solid-state palladation of AZB by $\left[\mathrm{Pd}(\mathrm{OAc})_{2}\right]_{3}$. Only alpha route is drawn. Possible trinuclear species are drawn in parenthesis. 
Mechanism. Widely-accepted mechanism for the $\mathrm{C}-\mathrm{H}$ bond activation by $\left[\mathrm{Pd}(\mathrm{OAc})_{2}\right]_{3}$ involves the $\mathrm{C}-\mathrm{H}$ bond activation by a Lewis-acidic metal via agostic interaction with the exiting proton and simultaneous acceptance of this proton by a basic ligand via an intramolecular hydrogen bond. ${ }^{[16]}$ Similar to the chloride precursors, an adduct should be formed by coordination of the substrate to $\left[\mathrm{Pd}(\mathrm{OAc})_{2}\right]_{3}$ before any $\mathrm{C}-\mathrm{H}$ bond cleavage takes place. ${ }^{[16]}$ Reaction is initiated by opening of the trimer $\left[\mathrm{Pd}(\mathrm{OAc})_{2}\right]_{3}$ by either the substrate or an additive, and this process yields a trimeric, dimeric or even monomeric acetate species. ${ }^{[16,17]}$ In our experiments, adducts have not been observed suggesting that their formation is slow and that, once present, they rapidly undergo the $\mathrm{C}-\mathrm{H}$ bond activation. and transform to the palladated products $\mathbf{d M}_{\alpha}-$ III or $\mathbf{d D}$-III. Thus, the opening of the trimer in the solid-state, either by the substrate or the liquid additive, is even slower than cleavage of the $\mathrm{C}-\mathrm{H}$ bond, which correlates with mechanistic studies for palladation of $\mathrm{N}$-donor ligands. ${ }^{[16]}$ Accordingly, the effect of liquid additives should correlate to their effect on breaking of the trimeric $\mathrm{Pd}$ precursor. More basic liquid should more efficiently compete with acetate ions in coordination to the Pd centers and could also facilitate the $\mathrm{C}-\mathrm{H}$ bond cleavage. This hypothesis has been supported by correlation of the observed LAG reaction rates with Gutmann's basicity ${ }^{[15]}$ of the employed liquid additives.

However, a more complex role of the additives is evident from the analysis of NG, LAG and ILAG experiments. NG of $\left[\mathrm{Pd}(\mathrm{OAc})_{2}\right]_{3}$ and $\mathbf{A Z B}$ is the slowest reaction which shows that all employed additives, including $\mathrm{AcOH}$, act beneficially to palladation by $\left[\mathrm{Pd}(\mathrm{OAc})_{2}\right]_{3}$. The ability of $\mathrm{H}_{2} \mathrm{O}$ and DMF to cleave $\left[\mathrm{Pd}(\mathrm{OAc})_{2}\right]_{3},{ }^{[18]}$ as well as to act as a proton shuttle, agrees with fast LAG-DMF and LAG- $\mathrm{H}_{2} \mathrm{O}$. AcOH could be involved in proton shuttling from the substrate to the coordinated acetate,${ }^{[19]}$ which might rationalize $\mathrm{LAG}-\mathrm{AcOH}$ being faster than NG even though the trimeric precursor in favored in presence of $\mathrm{AcOH}^{\left[{ }^{[18]}\right.}$

In order to further describe the effect of liquid additives, we performed LAG of $\left[\mathrm{Pd}(\mathrm{OAc})_{2}\right]_{3}$ without AZB and adding $15 \mu \mathrm{L}$ of each employed liquid under the same experimental conditions as in examined reactions with AZB. IR spectra of the reaction mixtures with DMF or $\mathrm{H}_{2} \mathrm{O}$ obtained after two hours of milling (Figure S35) show a minor amount of palladium acetate species other than $\left[\mathrm{Pd}(\mathrm{OAc})_{2}\right]_{3}$ which are most likely amorphous according to PXRD patterns that agree with the pattern of the trimer (Figure S52). In contrast, IR spectra of the reaction mixtures with $\mathrm{MeCN}$ and $\mathrm{AcOH}$ show no change with regard to the IR spectrum of $\left[\mathrm{Pd}(\mathrm{OAc})_{2}\right]_{3}$. We note that the product of the $\left[\mathrm{Pd}(\mathrm{OAc})_{2}\right]_{3}$ hydrolysis, $\left[\mathrm{Pd}_{3}(\mu-\mathrm{OH})(\mu-\mathrm{OAc})_{5}\right],{ }^{[18]}$ was not detected in any of the mixtures. These experiments suggest that AZB, along with the liquid additive, plays an important role in breaking of the trimeric structure to either a trimeric open structure, dimeric or even monomeric species (Scheme 2). Similar ligand effect was observed for cycloisomerization of enynes catalyzed by $\left[\mathrm{Pd}(\mathrm{OAc})_{2}\right]_{3}$ in solution. ${ }^{[20]}$ Taking into account that $\mathrm{LAG}$ reactions are faster than analogous ILAG reactions, we suggest that di- or monomeric species, which are formed in $\mathrm{AcOH}$ solution of $\left[\mathrm{Pd}(\mathrm{OAc})_{2}\right]_{3}$ and $\mathrm{NaOAc},{ }^{[21]}$ are not prevailing in LAG but might occur under ILAG conditions. This is supported by PXRD (Figure S53) and IR (Figure S36) analysis of the mixture obtained by IAG milling of $\left[\mathrm{Pd}(\mathrm{OAc})_{2}\right]_{3}$ with $\mathrm{NaOAc}$ for 2 hours. We presume that a stable DMF-acetate complex could be formed in ILAG-DMF which would consume the Pd precursor and stop the reaction. Analogous side reaction is not prominent with other additives that are O-ligands, allowing ILAG$\mathrm{H}_{2} \mathrm{O}$ and ILAG-AcOH to finish.

Taking the presented results into account, we propose that breaking of the trimer in LAG reactions starts predominantly with the coordination of AZB which is present in excess with respect to the liquid additive. Cleavage should give trinuclear intermediates ${ }^{[17]}$ that can be further cleaved by the employed liquid and/or AZB. These intermediates remained elusive as they could not be isolated or even detected by any employed spectroscopic method. This is similar to behavior of the unstable trinuclear complexes reported for the $\mathrm{C}-\mathrm{H}$ activation of acetanilides. ${ }^{[17 \mathrm{a}]}$ Hereafter, the trinuclear species enters the liquid-assisted $\mathrm{C}-\mathrm{H}$ bond activation accompanied by cleavage of the acetate bridges that ultimately leads to the dimeric palladated product. Inferior ILAG reactions could favor di- or monomeric intermediates and might be assisted by external acetate and/or the employed liquid. In all cases the final acceptor of the exiting proton is the acetate yielding $\mathrm{AcOH}$.

\section{Conclusion}

This paper describes a detailed comparative mechanistic study of the solid-state $\mathrm{C}-\mathrm{H}$ bond activation in the asymmetric azobenzene substrate by most common $\mathrm{Pd}(\mathrm{II})$ catalysts. Our results clearly demonstrate that $\mathrm{PdCl}_{2}$ and the highly electrophilic $\left[\mathrm{Pd}(\mathrm{MeCN})_{4}\right]\left[\mathrm{BF}_{4}\right]_{2}$ are more convenient catalysts for the solid-state $\mathrm{C}-\mathrm{H}$ bond activation than $\mathrm{PdCl}_{2}(\mathrm{MeCN})_{2}$ and $\left[\mathrm{Pd}(\mathrm{OAc})_{2}\right]_{3}$. A prominent effect of liquid and/or solid additives on the reactivity of different $\mathrm{Pd}(\mathrm{II})$ catalysts, the selected substrate and generated intermediates is observed by extensive in situ and ex situ spectroscopic studies. Proposed solid-state mechanisms agree with the mechanistic schemes suggested for the reactions in solution. Results for $\mathrm{PdCl}_{2}, \mathrm{PdCl}_{2}(\mathrm{MeCN})_{2}$ and $\left[\mathrm{Pd}(\mathrm{MeCN})_{4}\right]\left[\mathrm{BF}_{4}\right]_{2}$ support the two-step palladation via initial fast coordination of the precursor to the substrate forming the adduct that in the second slow step undergoes the $\mathrm{C}-\mathrm{H}$ bond cleavage. In contrast, breaking of the trimeric precursor is the slow step in the solid-state palladation by $\left[\mathrm{Pd}(\mathrm{OAc})_{2}\right]_{3}$.

The obtained mechanistic insight into the solid-state $\mathrm{C}-\mathrm{H}$ bond activation with different $\mathrm{Pd}(\mathrm{II})$ catalysts offers a better understanding of the effects of the metal catalyst as well as liquid and solid additives in future functionalization studies using ball milling. This might stimulate wider application of this type of solid-state reactions for synthesis of various compounds and materials, especially those that are not readily available from solution.

\section{Experimental Section}

General Measurements. Used chemicals and solvents are commercially available and were not additionally purified or dried. NMR spectra were recorded at $25^{\circ} \mathrm{C}$ in DMSO- $d_{6}, \mathrm{CDCl}_{3}$ or $\mathrm{MeCN}-d_{3}$ on Bruker AV-600, AV-400 and AV-300 spectrometers. Chemical shifts are referenced to the tetramethylsilane (TMS) internal standard and the assignment is given in Tables S3-S7. IR spectra were recorded on a Perkin-Elmer FT spectrometer Spectrum Two. Elemental analyses were performed on a Perkin-Elmer Series II $2400 \mathrm{CHNS} / \mathrm{O}$ analyzer. PXRD measurements were done on a PANalytical Aeris X-ray diffractometer with a Ni-filtered CuK $K_{a}$ radiation. 
Single-crystal X-ray diffraction. Single crystals of AZB, $\mathrm{mM}_{\alpha}-\mathrm{I}, \mathrm{mD}-\mathrm{I}$, $\mathbf{m M}_{\alpha}-\mathrm{II}, \mathbf{d M}_{\alpha}-\mathrm{III}$ and $\mathbf{d D}$-III were measured on an Oxford Diffraction Xcalibur Nova R using a microfocus $\mathrm{Cu}$ tube, whereas $\mathbf{m A}_{\alpha}-\mathbf{I}$ was measured on an Oxford Diffraction Xcalibur using a Mo tube and the CCD detector. CCDC 1836286-1836292 contain the supplementary crystallographic data for this paper. Crystal and other data is in Tables S1-S2.

Milling reactions. Experiments were performed using an IST500 mixer mill (www.insolidotech.com/ist500.html) with a built-in fan operating at 30 $\mathrm{Hz}$. To assure data consistency, reported experiments with each precursor were run consecutively under analogous conditions and at ambient temperature of $22 \pm 2{ }^{\circ} \mathrm{C}$. Reactions were conducted in poly(methylmetacrylate) (PMMA) transparent jars $(14 \mathrm{~mL})$ that allowed for in situ Raman monitoring. One zirconium(IV) oxide $\left(\mathrm{ZrO}_{2}, 12 \mathrm{~mm}, 4.4\right.$ g) or one stainless steel $(10 \mathrm{~mm}, 4.0 \mathrm{~g})$ milling ball was used. Reactions were performed starting with ca. $225 \mathrm{mg}$ of the reaction mixture. Salts $\left(\mathrm{NaOAc}, \mathrm{NaBF}_{4}\right.$ ) and/or $15 \mu \mathrm{L}$ of liquid (DMF, $\mathrm{AcOH}, \mathrm{H}_{2} \mathrm{O}$ or $\mathrm{MeCN}$ ) were used as additives. More details are in the Supporting Information. Volume of the liquid additives was adjusted to $15 \mu \mathrm{L}$ as this is the maximum volume of DMF that still allows good mixing inside the jar and is applicable to all employed liquids. Binary mixtures of liquids were not examined. According to the spectral data, all reactions are quantitative, however, isolation of the products results in a loss of material and thus can reduce the yield down to $80 \%$. According to ${ }^{1} \mathrm{H}$ NMR a slightly longer reaction time is needed to achieve a homogenous bulk than is the time determined by Raman analysis due to inherent lower sensitivity of the solid-state Raman spectroscopy with respect to ${ }^{1} \mathrm{H}$ NMR.

Solution-based reactions affording $\mathrm{mA}_{\alpha}-\mathrm{I}, \mathrm{mM}_{\alpha}-\mathrm{I}, \mathrm{dM}-\mathrm{I}, \mathrm{mD}-\mathrm{I}, \mathrm{dM}_{\alpha}-\mathrm{III}$ and $\mathbf{d D}$-III were conducted at room temperature. More details are in the Supporting Information.

In situ Raman monitoring was performed using a portable Raman system with a PD-LD (now Necsel) BlueBox laser source with a $785 \mathrm{~nm}$ excitation wavelength equipped with B\&W-Tek fiber optic Raman BAC102 probe and coupled with OceanOptics Maya2000Pro spectrometer with $4 \mathrm{~cm}^{-1}$ spectral resolution. Position of the probe was around $1 \mathrm{~cm}$ under the PMMA jar with laser beam focused about $1 \mathrm{~mm}$ inside of the jar. Time-resolved in situ Raman spectra were automatically collected. Subtraction of the jar contribution to the Raman spectra was described in details in reference $12 \mathrm{~d}$.

Analysis of Raman spectra. Spectral range of $1096-1640 \mathrm{~cm}^{-1}$ was baseline-corrected using asymmetric least squares ${ }^{[22 a]}$ (AsLS) and subsequently normalized using $\mathrm{I} 2 \mathrm{norm}$. Spectra were arranged in a data matrix that was used in multivariate curve analysis - alternate least squares (MCR-ALS) ${ }^{[22 b]}$ procedure in MATLAB to extract concentration and spectral contributions. To assure physically meaningful results and reduce rotational ambiguities, ${ }^{[22 c]}$ additional constraints were used, i.e. non-negativity and unimodality in concentration and non-negativity in spectral contributions. After optimization, derived MCR spectra were compared to the known Raman spectra of reactants and products. Raman spectra of the studied solids were assigned using literature data [11,23] and quantum-chemical calculations (see the Supporting Information).

\section{Acknowledgements}

We acknowledge mr. sc. Željko Marinić and Nikolina Višić for NMR measurements. Computations were done on the Isabella cluster at SRCE, Zagreb. This work has been supported by the Croatian Science Foundation under projects IP-2014-09-7984 and UIP-2014-09-4744.

Keywords: $\mathrm{C}-\mathrm{H}$ bond activation $\cdot$ mechanism $\cdot$ solid state $\cdot$ palladium $\cdot$ spectroscopy

[1] a) J. J. Topczewski, P.J. Cabrera, N. I. Saper, M. S. Sanford, Nature 2016, 531, 220-224; b) T. W. Lyons, M. S. Sanford, Chem, Rev. 2010 110, 1147-1169; c) A. R. Dick, K.L. Hull, M.S. Sanford, J. Am. Chem. Soc. 2004, 126, 2300-2301; d) A. McNally, B. Haffemayer, B. S. L. Collins, M. J. Gaunt, Nature, 2014, 510, 129-133; e) J. Yamaguchi, A. D. Yamaguchi, K. Itami, Angew. Chem. Int. Ed. 2012, 51, 8960-9009; f) L. Ackermann, Chem. Rev. 2011, 111, 1315-1345; g) K. Godula, D. Sames, Science, 2006, 312, 67-72.

[2] a) M. Albrecht, Chem. Rev. 2010, 110, 576-623; b) Palladacycles: Synthesis, Characterization and Applications (Eds. J. Dupont, M Pfeffer), Wiley-VCH, Weinheim, 2008; b) J. Dupont, C. S. Consorti, J. Spencer, Chem. Rev. 2005, 105, 2527-2572.

[3] a) M. Ghedini, I. Aiello, A. Crispini, A. Golemme, M. La Deda, D. Pucci, Coord. Chem. Rev. 2006, 250, 1373-1390; b) S.-H. Li, C.-W. Yu, J.-G. Xu, Chem. Commun. 2005, 450-452; c) A. C. F. Caires, Med. Chem. 2007, 7, 484-491; d) M. Juribašić, M. Ćurić, K. Molčanov, D. MatkovićČalogović, D. Babić, Dalton Trans. 2010, 39, 8769-8778; e) D. Cinčić, M. Juribašić, D. Babić, K. Molčanov, P. Šket, J. Plavec, M. Ćurić, Chem. Commun. 2011, 47, 11543-11545; f) M. Juribašić Kulcsár, I. Halasz, D. Babić, D. Cinčić, J. Plavec, M. Ćurić, Organometallics, 2014, 33, 12271234.

[4] A. Monas, K. Užarević, I. Halasz, M. Juribašić Kulcsár, M. Ćurić, Chem. Commun. 2016, 52, 12960-12963.

[5] a) M. Juribašić, A. Budimir, S. Kazazić, M. Ćurić, Inorg. Chem. 2013, 52 , 12749-12757; b) D. Babić, M. Ćurić, K. Molčanov, G. Ilc, G.; J. Plavec, Inorg. Chem. 2008, 47, 10446-10454.

[6] a) S. Nakamatsu, S. Toyota, W. Jones, F. G. Toda, Chem. Commun. 2005, 3808-3810; b) M.J. Cliffe, C. Mottillo, D. K. Bučar, T. Friščić, Chem. Sci. 2012, 3, 2495-2500. c) M. Juribašić Kulcsár, I. Halasz, A
Budimir, K. Užarević, S. Lukin, A. Monas, F. Emmerling, J. Plavec, M. Ćurić, Inorg. Chem. 2017, 56, 5342-5351.

[7] a) S. L. James, C. J. Adams, C. Bolm, D. Braga, P. Collier, T. Friščić, F Grepioni, K. D. M. Harris, G. Hyett, W. Jones, A. Krebs, J. Mack, L. Maini, A. G. Orpen, I. P. Parkin, W. C. Shearouse, J. W. Steed, D. C. Waddell, Chem. Soc. Rev. 2012, 41, 413-417; b) T. Friščić, Chem. Soc Rev. 2012, 41, 3493-3510; c) G.-W. Wang, Chem. Soc. Rev. 2013, 42, 7668-7700; d) V. Declerck, P. Nun, J. Martinez, F. Lamaty, Angew. Chem. Int. Ed. 2009, 48, 9318-9321; e) D. Braga, L. Maini, F. Grepioni, Chem. Soc. Rev. 2013, 42, 7638-7648. f) N. R. Rightmire, T. P. Hanusa, Dalton Trans. 2016, 45, 2352-2362; g) J. Andersen, J. Mack, Green Chem. 2018, 20, 1435-1443.

[8] a) E. Boldyreva, Chem. Soc. Rev. 2013, 42, 7719-7738; b) V. Šepelak A. Düvel, M. Wilkening, K. D. Becker, P. Heitjans, Chem. Soc. Rev. 2013, 42, 7507-7520; c) R. Janot, D. Guerard, Prog. Mater. Sci. 2005, 50, 1-92; d) J. L. Howard, Q. Cao, D. L. Browne, Chem. Sci. 2018, 9 , 3080-3094.

[9] a) J. G. Hernández, C. Bolm, J. Org. Chem. 2017, 82, 4007-4019; b) J. G. Hernandez, Chem. Eur. J. 2017, 23, 17157-17165; c) S. Zhao, Y. Li, C. Liu, Y. Zhao, Tetrahedron Lett. 2018, 59, 317-324.

[10] a) G. N. Hermann, C. Bolm, ACS Catal. 2017, 7, 4592-4596; b) G. N. Hermann, C. L. Jung, C. Bolm, Green Chem. 2017, 19, 2520-2523; c) G. N. Hermann, P. B. Becker, C. Bolm, Angew. Chem. Int. Ed. 2016, 55, 3781-3784; d) L. Chen, M. Regan, J. Mack, ACS Catal. 2016, 6, 868872; e) K.-Y. Jia, J.-B. Yu, Z.-J. Jiang, W.-K. Su, J. Org. Chem. 2016, 81, 6049-6055; f) S.-J. Lou, Y.-J. Mao, D.-Q. Xu, J.-Q. He, Q. Chen, Z. Y. Xu, ACS Catal. 2016, 6, 3890-3894; g) G. N. Hermann, P. B. Becker C. Bolm, Angew. Chem. Int. Ed. 2015, 54, 7414-7417; h) J.-L. Do, C. Mottillo, D. Tan, V. Štrukil, T. Friščić, J. Am. Chem. Soc. 2015, 137, 
2476-2479; i) D. V. Aleksanyan, S. G. Churusova, R. R. Aysin, Z. S Klemenkova, Y. V. Nelyubina, V. A. Kozlov, Inorg. Chem. Commun. 2017, 76, 33-35.

[11] M. Juribašić, K. Užarević, D. Gracin, M. Ćurić, Chem. Commun. 2014, 50, 10287-10290.

[12] a) T. Friščić, I. Halasz, P.J. Beldon, A. M. Belenguer, F. Adams, S. A. J. Kimber, V. Honkimäki, R. E. Dinnebier, Nature Chem. 2013, 5, 66-73 b) D. Gracin, V. Štrukil, I. Halasz, K. Užarević, Angew. Chem. Int. Ed. 2014, 53, 6193-6197; c) L. Batzdorf, F. Fischer, M. Wilke, K.-J. Wenzel, F. Emmerling, Angew. Chem. Int. Ed. 2015, 54, 1799-1802; d) S. Lukin T. Stolar, M. Tireli, M. V. Blanco, D. Babić, T. Friščić, K. Užarević, I. Halasz, Chem. Eur. J. 2017, 23, 13941-13949.

[13] M. Ćurić, D. Babić, Ž. Marinić, Lj. Paša-Tolić, V. Butković, J. Plavec, Lj. Tušek-Božić, J. Organomet. Chem. 2003, 687, 85-99.

[14] D. Babić, M. Ćurić, D. M. Smith, J. Organomet. Chem. 2011, 696, 661669.

[15] a) W. R. Fawcett, J. Phys. Chem. 1993, 97, 9540-9546; b) M. Tireli, M. Juribašić Kulcsár, N. Cindro, D. Gracin, N. Biliškov, M. Borovina, M. Ćurić, I. Halasz, K. Užarević, Chem. Commun. 2015, 51, 8058-8061.

[16] a) D. L. Davies, S. A. Macgregor, C. L. McMullin, Chem. Rev. 2017, 117, 8649-8709; b) D. Lapointe, K. Fagnou, Chem. Lett. 2010, 39 , 1119-1126; c) J. Granell, M. Martinez, Dalton Trans. 2012, 41, 11243 11258; e) B. E. Haines, J. F. Berry, J.-Q. Yu, D. G. Musaev, ACS Catal. 2016, 6, 829-839.
[17] a) J. Váňa, J. Lang, M. Šoltésová, J. Hanusek, A. Růžička, M. Sedlák, J. Roithová, Dalton Trans. 2017, 46, 16269-16275; b) J. Váňa, J. Hanusek, M. Sedlák, Dalton Trans. 2018, 47, 1378-1382; c) V. K. Jain, L. Jain, Coord. Chem. Rev. 2010, 254, 2848-2903; d) W. Bauer, M. Prem, K. Polborn, K. Sünkel, W. Steglich, W. Beck, Eur. J. Inorg. Chem. 1998, 485-493.

[18] a) R. B. Bedford, J. G. Bowen, R. B. Davidson, M. F. Haddow, A. E. Seymour-Julen, H. A. Sparkes, R. L. Webster, Angew. Chem. Int. Ed. 2015, 54, 6591-6594; b) W. Rauf, J. M. Brown, Chem. Commun. 2013 49, 8430-8440. c) L. A. Adrio, B. N. Nguyen, G. Guilera, A. G. Livingston, K. K. Hii, Catal. Sci. Technol. 2012, 2, 316-323.

[19] a) R. B. Sunoj, M. Anand, Phys. Chem. Chem. Phys. 2012, 14, 12715 12736; b) J. Ma, K. Chen, H. Fu, L. Zhang, W. Wu, H. Jiang, S. Zhu, Org. Lett. 2016, 18, 1322-1325.

[20] A. Mekareeya, P. R. Walker, A. Couce-Rios, C. D. Campbell, A. Steven, R. S. Paton, E. A. Anderson, J. Am. Chem. Soc. 2017, 139, 1010410114.

[21] R. N. Pandey, P. M. Henry, Can. J. Chem. 1974, 52, 1241-1247.

[22] a) P. H. C. Eilers, H. F. M. Boelens. Baseline Correction with Asymmetric Least Squares Smoothing, Leiden University Medical Center Report, 2015; b) J. Jaumot, A. de Juan, R. Tauler, Chemom. Intel. Lab. Syst. 2015, 140, 1-12; c) A. de Juan, J. Jaumot, R. Tauler Anal. Methods, 2014, 6, 4964-4976.

[23] G. Socrates, Infrared and Raman Characteristic Group Fre-quencies 3rd ed. John Wiley \& Sons, Chichester, 2001.
Mechanism of the solid-state $\mathrm{C}-\mathrm{H}$ bond activation by various $\mathrm{Pd}(\mathrm{II})$ catalysts under milling conditions is studied by in situ Raman and ex situ IR, NMR and PXRD methods. Reaction dynamics, intermediates involved in the reaction and effects of liquid and solid additives have been identified using spectroscopic data as well as the reaction profiles obtained from the analysis of the in situ Raman data.

Alen Bjelopetrović, Stipe Lukin, Ivan Halasz, Krunoslav Užarević, Ivica Đilović, Dajana Barišić, Ana Budimir Marina Juribašić Kulcsár ${ }^{\star}$ and Manda Ćurić*

((Insert TOC Graphic here: max. width: $5.5 \mathrm{~cm}$; max. height: $5.0 \mathrm{~cm}$ ))

\author{
Page 1. - Page 11. \\ Mechanism of Solid-State C-H Bond \\ Activation by $\mathrm{Pd}(\mathrm{II})$ Catalysts
}

